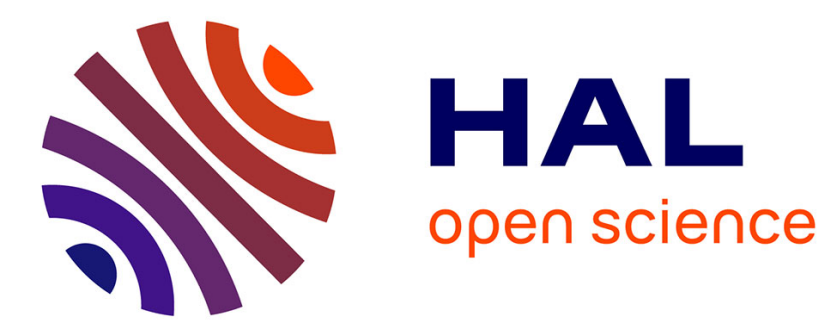

\title{
Current antifungal treatment of fusariosis
}

\author{
Abdullah M. S. Al-Hatmi, Alexandro Bonifaz, Stephane Ranque, G. Sybren \\ De Hoog, Paul E. Verweij, Jacques F. Meis
}

\section{To cite this version:}

Abdullah M. S. Al-Hatmi, Alexandro Bonifaz, Stephane Ranque, G. Sybren De Hoog, Paul E. Verweij, et al.. Current antifungal treatment of fusariosis. International Journal of Antimicrobial Agents, 2018, 51 (3), pp.326-332. 10.1016/j.ijantimicag.2017.06.017 . hal-01789209

\section{HAL Id: hal-01789209 \\ https://hal.science/hal-01789209}

Submitted on 12 Apr 2019

HAL is a multi-disciplinary open access archive for the deposit and dissemination of scientific research documents, whether they are published or not. The documents may come from teaching and research institutions in France or abroad, or from public or private research centers.
L'archive ouverte pluridisciplinaire HAL, est destinée au dépôt et à la diffusion de documents scientifiques de niveau recherche, publiés ou non, émanant des établissements d'enseignement et de recherche français ou étrangers, des laboratoires publics ou privés. 
Themed Issue: New challenges in antifungal therapy

\title{
Current antifungal treatment of fusariosis
}

\author{
Abdullah M.S. Al-Hatmi a,b,c,*, Alexandro Bonifaz d , Stephane Ranque e, \\ G. Sybren de Hoog a,f,g,h, Paul E. Verweij ${ }^{c, i}$, Jacques F. Meis ${ }^{c, i, j}$ \\ a Westerdijk Fungal Biodiversity Institute, Utrecht, The Netherlands \\ b Directorate General of Health Services, Ministry of Health, Ibri Hospital, Ibri, Oman \\ ' Centre of Expertise in Mycology Radboudumc/Canisius-Wilhelmina Ziekenhuis, Nijmegen, The Netherlands \\ ' Hospital General de México, 'Dr. Eduardo Liceaga', Mexico City, Mexico \\ e Aix Marseille Univ, IRD, AP-HM, SSA, VITROME, IHU-Méditerranée Infection, Marseille, France \\ ${ }^{\mathrm{f}}$ Institute of Biodiversity and Ecosystem Dynamics, University of Amsterdam, Amsterdam, The Netherlands \\ g Basic Pathology Department, Federal University of Paraná State, Curitiba, Paraná, Brazil \\ h Biological Sciences Department, Faculty of Science, King Abdulaziz University, Jeddah, Saudi Arabia \\ i Department of Medical Microbiology, Radboud University, Nijmegen Medical Centre, Nijmegen, The Netherlands \\ j Department of Medical Microbiology and Infectious Diseases, Canisius Wilhelmina Hospital, Nijmegen, The Netherlands
}

A R T I C L E I N F O

\section{Keywords:}

Fusariosis

Keratitis

Natamycin

Voriconazole

Posaconazole

Fusarium

\begin{abstract}
A B S T R A C T
Fungi of the genus Fusarium are well known as major plant pathogens and soil inhabitants, but also cause a broad spectrum of human infections. Fusariosis is the second most common mould infection after aspergillosis, and keratitis is the most encountered implantation infection in immunocompetent individuals. Natamycin is active against Fusarium species both in vitro and in vivo, and is used along with voriconazole as the mainstay of treatment for Fusarium keratitis. Onychomycosis is treated with terbinafine, voriconazole and sometimes itraconazole. Cure is possible despite high in vitro minimum inhibitory concentrations (MICs). Recently, disseminated infections have increased dramatically, mainly affecting severely immunocompromised patients. The remarkable intrinsic resistance of Fusarium species to most antifungal agents results in high mortality rates in this patient population. Recovery of neutropenia is essential for patient survival and treatment should include voriconazole or amphotericin B as first-line and posaconazole as salvage therapy.
\end{abstract}

(C) 2017 Elsevier B.V. and International Society of Chemotherapy. All rights reserved.

\section{Introduction}

The fungal genus Fusarium (order Hypocreales) contains numerous plant-pathogenic species, and also human opportunistic pathogens causing eye, skin, nail and disseminated infections. The first published human case of fusariosis was an eye infection in 1958, and soon thereafter other types of disease were reported $[1,2]$. The genus has been subjected to several radical taxonomic revisions. Older, morphological subdivisions of the genus into sections did not match with phylogeny. Modern, polyphasic taxonomy has led to narrow species concepts with numerous micro-species, which are aggregated into 20 species complexes [3]. In Fusarium, a species complex is defined as a cluster of closely related entities that exhibit similar physiological and molecular features, and serve

\footnotetext{
* Corresponding author. Westerdijk Fungal Biodiversity Institute, PO Box 85167, 3508 AD, Utrecht, The Netherlands.

E-mail address: abdullaalhatmi@gmail.com (A.M.S. Al-Hatmi).
}

as an alternative to the subgeneric 'sections' currently in use in e.g. Aspergillus $[4,5]$.

Of the more than 300 recognised species to date, about a quarter has been isolated from humans, mostly causing superficial infections, such as onychomycosis or keratitis in immunocompetent individuals [2]. Fusarium keratitis was originally observed mainly among farmers and outdoor workers, but the widespread use of contact lenses has dramatically increased the incidence of keratitis among urban populations [6,7]. Onychomycosis is a common condition in otherwise healthy humans, with up to $10 \%$ of cases caused by Fusarium [8]. Deep and disseminated fusariosis have occasionally been documented, exclusively in patients with haematological malignancies and other conditions associated with immunosuppression [9]. Agents of any type of fusariosis are mainly found in three species complexes: F. solani complex (FSSC), F. oxysporum complex (FOSC) and F. fujikuroi complex (FFSC). The F. dimerum, F. incarnatum-equiseti, and F. chlamydosporum species complexes are rare causes of human infections [10]. Fusarium shows a remarkably high degree of intrinsic resistance to a wide spectrum of commonly used antifungals. The objective of the present 
paper was to review the current status of antifungal therapy of fusariosis, highlighting the best options for infection management.

\section{Methods}

\subsection{Literature}

The majority of the literature we reviewed that was related to treatment was based on case reports and in vitro and in vivo studies of drug susceptibilities. We assessed and collected leading articles on drugs that are available and have been used successfully in patients with fusariosis. Phylogeny and resistance, treatment of different infections (onychomycosis, keratitis and deep and invasive infection), in vitro antifungal susceptibility patterns, drug interactions, dose, and duration of treatment were considered. We selected publications most useful for readers interested in the medical management of Fusarium infections.

\subsection{Phylogeny}

The partial sequence of 28S rRNA retrieved from the National Center for Biotechnology Information (NCBI) was used to construct a phylogenetic tree of the Ascomycota, Basidiomycota and some other ancestral lineages, mainly showing the members that have been implicated in human diseases. The tree was constructed based on 28S rDNA sequences $(\mathrm{n}=414)$ aligned by MAFFT, using a neighbour-joining algorithm with Kimura correction (Fig. 1). Orders represented by blue boxes are those where nearly all members have high intrinsic resistance to a wide panel of antifungal drugs. These groups of fungi share a high degree of intrinsic resistance to most currently used antifungal agents and belong to different orders. Fusarium with Acremonium and Trichoderma belong to the order
Hypocreales, whereas Microascus, Scopulariopsis, Scedosporium and Lomentospora are in the adjacent order, Microascales.

\section{Identity and resistance}

A robust taxonomy of the fungi requires species validation with the inclusion of ex-type specimens and establishment of phylogenetic relationships [4]. Species redefinitions have uncovered numerous Fusarium species responsible for infections that were previously unrecognised in the older literature. The phylogenetic approach also enables comparison of susceptibility data at the species, genus, and family level, showing trends in intrinsic resistance over larger groups of organisms. Fusarium species share their high degree of intrinsic resistance to most currently used antifungal agents with Acremonium and Trichoderma, which belong to the same order Hypocreales, and with Microascus, Scopulariopsis, Scedosporium and Lomentospora in the adjacent order Microascales [2]. Intrinsic multiresistance of these fungi is unique among the Ascomycota (Fig. 1), and indicates that this property was acquired in a common ancestor of the two orders. However, knowledge is scant on resistance mechanisms in Fusarium and relatives, and evolutionary relationships have not been established. Intrinsic resistance interferes with antifungal therapy and is particularly difficult in patients with prolonged immunosuppression or failure to come into remission of their haematological disease [6]. Insufficient documentation is available on the correlation of in vitro susceptibility test results and in vivo outcome, so no clinical breakpoints have been determined, but epidemiological cut-off values have been recently established for several Fusarium species [11].

The spectrum of Fusarium species causing human infection is globally increasing [10]. Recent molecular phylogenetic studies provided support for the recognition of additional cryptic species [2,3].

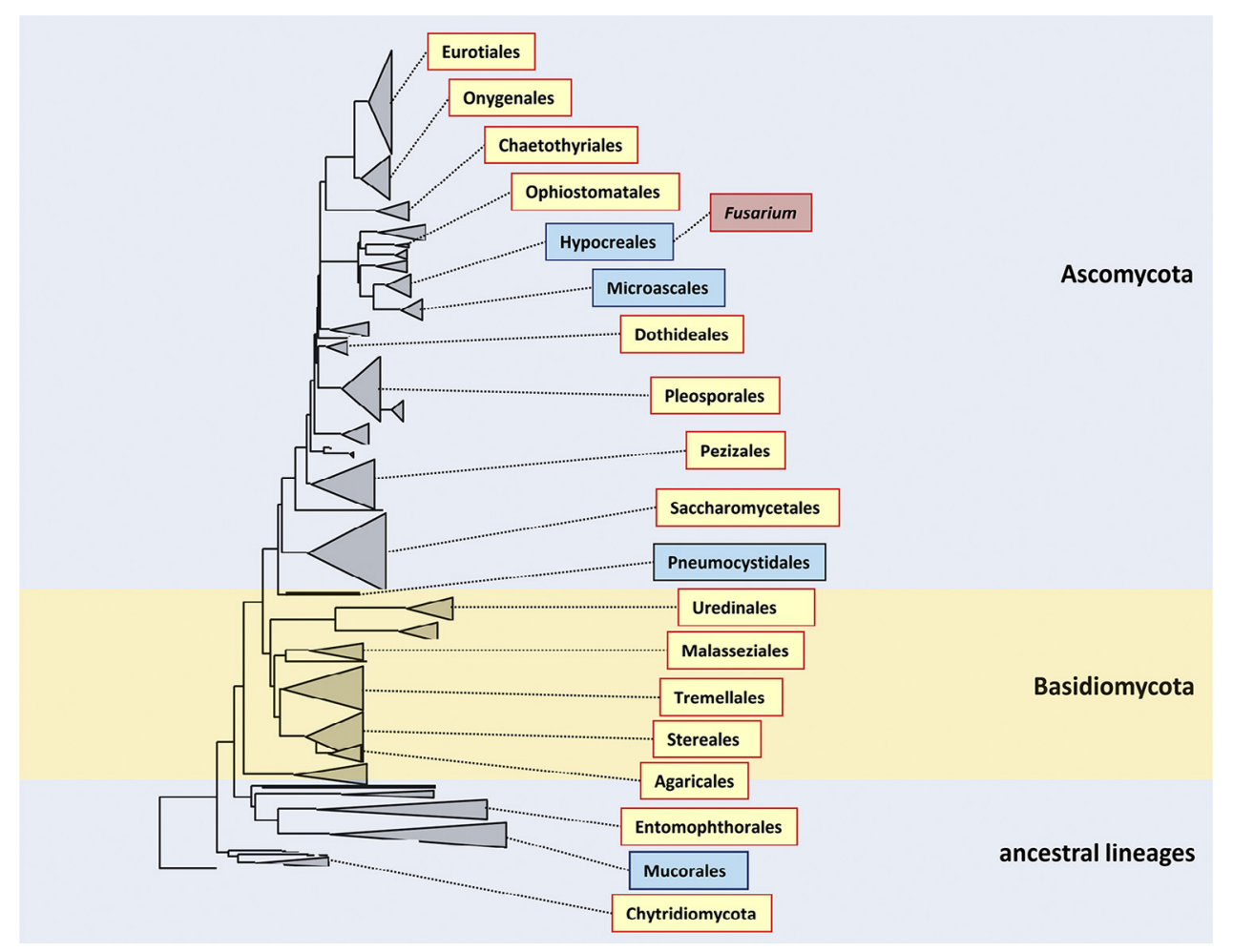

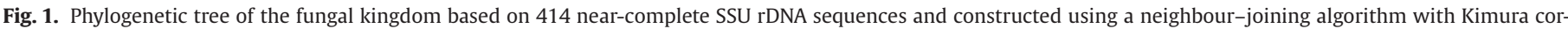

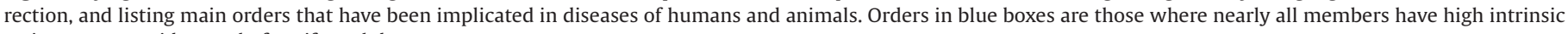
resistance to a wide panel of antifungal drugs. 
Table 1

MIC ranges of amphotericin B, voriconazole, posaconazole, natamycin and terbinafine for the clinical Fusarium strains. ${ }^{a}$

\begin{tabular}{|c|c|c|c|c|c|c|}
\hline \multirow[t]{2}{*}{ Species complex } & \multirow{2}{*}{$\frac{\text { Fusarium species (n) }}{\text { Clinical strains (107) }}$} & \multicolumn{5}{|c|}{ MICs [range; $\mu \mathrm{g} / \mathrm{mL}$ ] } \\
\hline & & AMB & VRC & PSC & NATA & TBF \\
\hline \multirow[t]{7}{*}{ F. solani complex (FSSC) } & F. keratoplasticum (10) & $1-2$ & $4-16$ & $8-16$ & $2-4$ & $8-16$ \\
\hline & F. falciforme (10) & $0.5-2$ & $4-16$ & $1-16$ & $2-4$ & $1-8$ \\
\hline & F. solani sensu stricto (FSS5) (5) & $1-2$ & 16 & 16 & 4 & - \\
\hline & F. lichenicola (5) & 0.5 & $1-16$ & 16 & 4 & $>2$ \\
\hline & F. petroliphilum (5) & $1-2$ & $8-16$ & $8-16$ & 4 & - \\
\hline & F. metavorans (FSS6) (2) & 1 & 16 & 16 & 4 & - \\
\hline & F. pseudoniforme (1) & 0.5 & 8 & 4 & 4 & - \\
\hline F. oxysporum complex (FOSC) & F. oxysporum (5) & $0.5-2$ & $2-8$ & $0.5-16$ & 4 & $2-8$ \\
\hline \multirow{14}{*}{ F. fujikuroi complex (FFSC) } & F. acutatum (3) & $1-2$ & $1-16$ & $1-16$ & 4 & - \\
\hline & F. ananatum (5) & $0.125-2$ & $1-4$ & $0.5-1$ & 4 & - \\
\hline & F. andiyazi (1) & 1 & 2 & 1 & 4 & - \\
\hline & F. anthopilum (1) & 0.5 & 1 & 0.5 & 4 & - \\
\hline & F. fujikuroi (5) & $0.25-1$ & $1-8$ & $1-2$ & 4 & \\
\hline & F. musae (4) & $4-8$ & $1-8$ & $8->16$ & - & $2-4$ \\
\hline & F. napiforme (4) & $1-8$ & $1-4$ & $2->16$ & 4 & $0.5-1$ \\
\hline & F. nygamai (5) & $1-4$ & $1-16$ & $8->16$ & 4 & $0.125-2$ \\
\hline & F. proliferatum (5) & $0.5-2$ & $2-8$ & $1->16$ & 4 & $0.25-1$ \\
\hline & F. sacchari (5) & $0.5-1$ & $1-4$ & $0.5->16$ & 4 & $0.5-1$ \\
\hline & F. subglutinans (2) & $0.5-1$ & $1-2$ & $0.125-0.25$ & 4 & - \\
\hline & F. temperatum (1) & 0.25 & 1 & 0.25 & 4 & - \\
\hline & F. thapsinum (5) & $1-2$ & $1-4$ & $2->16$ & 4 & $0.25-1$ \\
\hline & F. verticilliodes (5) & $1-2$ & $1-4$ & $0.25-1$ & 4 & $0.25-0.5$ \\
\hline \multirow[t]{2}{*}{ F. dimerum complex (FDSC) } & F. delphinoides (3) & $1-2$ & $1-4$ & $2->16$ & 4 & - \\
\hline & F. dimerum (5) & $0.5-1$ & $2-4$ & $2->16$ & 4 & $1-2$ \\
\hline \multirow{2}{*}{ F. incarnatum-equiseti complex (FIESC) } & F. incarnatum (2) & $0.5-2$ & $2-4$ & $4-8$ & 4 & $1-2$ \\
\hline & F. equiseti (2) & $0.5-1$ & & $4-16$ & 4 & - \\
\hline F. chlamydosporum complex (FDSC) & F. chlamydosporum (1) & 4 & 2 & $>16$ & 4 & $0.25-1$ \\
\hline
\end{tabular}

a AMB, amphotericin B; VRC, voriconazole; PSC, posaconazole; NATA, natamycin; TBF, terbinafine; '-', no data available for the species.

Developments in taxonomy of Fusarium have had a major impact on our understanding of drug susceptibility profiles and speciesspecific differences between the newly recognised species [12]. For example, Fusarium solani complex exhibits in vitro susceptibility profiles that on average are higher than those of the Fusarium fujikuroi complex [13]. Minimum inhibitory concentrations (MICs) are generally $>4 \mu \mathrm{g} / \mathrm{mL}$ for both posaconazole and voriconazole for most species. Despite these modest activities, both triazoles have been used successfully in patients with amphotericin B-refractory fusariosis (Table 1) [14-16]. There is an ongoing, prospective, multicentre study recruiting participants to evaluate the safety of voriconazole in the treatment of invasive aspergillosis and rare moulds, including Fusarium in children (ClinicalTrials.gov identifier: NCT00836875), but results have not yet been published.

Although resistance mechanisms in Fusarium are not entirely understood, amino acid alterations and/or overexpression of

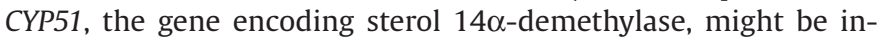
volved in azole resistance, similar to Aspergillus [17]. On the other hand, prolonged use of triazoles in the environment has raised concern about acquired resistance in Sporothrix spp., Candida albicans, Cryptococcus neoformans and Aspergillus fumigatus [18-21]. However, in the latter, fungi resistance develops among previously susceptible strains after exposure to the antifungal agent.

In most fungi, clinical isolates are thought to be more resistant to antifungals than environmental isolates, because of antimicrobial exposure during prolonged therapy in chronically-infected patients. As Fusarium is intrinsically resistant, i.e. strains are not susceptible even prior to confrontation with the antifungal, all isolates of a species show similar behaviour. Pujol et al compared 38 strains of clinical origin and 20 from environmental sources against different drugs and demonstrated similar activity against both groups of fungi [22]. The MIC values were generally high, with the only exceptions being amphotericin $\mathrm{B}$ and ketoconazole, which were more active against the environmental strains. However, many structurally similar antifungals, including azoles, are used in both hospitals and agriculture, and show similar susceptibility profiles against both clinical and environmental isolates of Fusarium spp. [23].

\section{Onychomycosis}

Fusarium onychomycosis is one of the most common nondermatophyte mould infections [24]. Frequencies vary between $1 \%$ and 16\% [25,26]. Appropriate treatment is recommended because of the risk of dissemination from a local nail lesion upon increased immunosuppression [27]. The infections are clinically indistinguishable from onychomycosis by dermatophytes, and present as distal subungual, proximal subungual and total dystrophic infections $[25,26]$. Fusarium paronychia is often associated with onychomycosis and is characterised by periungual purulent inflammation, similar to that induced by Candida species [28,29]. The main species complexes responsible for onychomycosis are $F$. oxysporum and F. solani, with F. fujikuroi being less frequently involved [30]. Direct examination with $\mathrm{KOH}$ reveals thin, irregular hyphae, and confirmation of aetiology is by repeated culture and absence of growth of dermatophytes and yeasts [25]. Dermatophytes are susceptible to terbinafine and voriconazole, whereas Fusarium species show higher MICs, with large variability $[2,23,31]$. Fusarium dimerum is the complex with the lowest MIC ranges and is mostly susceptible to itraconazole $(0.03-16 \mu \mathrm{g} / \mathrm{mL})$, terbinafine $(0.03-0.5 \mu \mathrm{g} / \mathrm{mL})$ and voriconazole $(0.5-8 \mu \mathrm{g} / \mathrm{mL})$, whereas $F$. oxysporum is more susceptible to terbinafine $(0.25-16 \mu \mathrm{g} / \mathrm{mL})$ than to other antifungals. Fusarium solani, the most commonly isolated species complex, has high MICs for all antifungals, ranging from 16 to $64 \mu \mathrm{g} / \mathrm{mL}$ [32]. All species are resistant to fluconazole, and studies with posaconazole show large variations (range $0.5-16 \mu \mathrm{g} / \mathrm{mL}$ ) [23,33,34].

Therapeutic outcome of Fusarium onychomycosis, particularly subungual cases, is variable. Itraconazole is usually applied at doses of 200 to $400 \mathrm{mg} / \mathrm{d}$, either daily or intermittently (pulse therapy). A second commonly used drug is terbinafine at doses of 250 to $500 \mathrm{mg} / \mathrm{d}$, sometimes combined with topical ciclopirox and 
amorolfine lacquer, or with keratolytics, such as urea $[28,29]$. Fusarium paronychia can be treated with the drugs mentioned or with topical treatment, preferably occlusive to achieve better concentrations in skin and nails [35].

\section{Keratitis}

Fusarium keratitis is one of the most common causes of mycotic keratitis and can cause irreversible blindness. The infection usually develops from trauma, particularly with vegetable matter, contact lenses, foreign bodies, or surgery, and is favoured by empirical topical antibiotics and steroids [36]. It is characterised by inflammation, conjunctival erythema and an irregular central corneal ulcer (80\%), with raised edges and growth in extension and depth, and there may be hypopyon, satellite lesions and corneal opacity [36]. Early diagnosis with direct microscopic examination, culture of the fungus and specific polymerase chain reaction (PCR) is essential. As in other fusariosis, keratitis is mainly caused by the $F$. solani and $F$. oxysporum complexes, and less frequently by F. dimerum, F. chlamydosporum, and F. temperatum [37,38]. In vitro susceptibility results show that variable MICs are obtained with amphotericin B and voriconazole [39].

Multiresistance limits the antifungal treatment options for Fusarium keratitis. Amphotericin B is usually very irritating to the corneal epithelium. It can be used intercamerally and intrastromally, but in randomised controlled trials this drug did not show greater efficacy than topical application (eye drops). However, it is mostly active after endophthalmitis has developed, and it is the compound that reduces hypopyon quickly $[40,41]$. A recent in vivo study in rabbits showed that amphotericin B combined with a chitosanmodified nanostructure lipid carrier decreases ophthalmic irritation and promotes drug penetration, with chitosan being an effective transport vehicle in keratin [42].

Natamycin $5 \%$ has been the most widely used topical polyene for keratitis, and although in vitro results show relatively high MICs in most Fusarium strains, it proved to be effective in clinical trials $[23,36,43]$. For example, Sharma et al concluded that it is more effective than voriconazole (1\%), and considered it the best antifungal for use as monotherapy, particularly in incipient cases [44]. O’Day et al recommended natamycin $5 \%(50 \mathrm{mg} / \mathrm{mL})$ solution as first choice for treatment of filamentous fungal keratitis, including Fusarium, particularly in superficial infections [45]. Lalitha et al reported that natamycin has a lower relative MIC than amphotericin B in a comparative study of different antifungal agents [46]. In another clinical trial comparing the efficacy of natamycin vs. voriconazole, there was no difference between the two drugs in terms of healing time and final visual acuity [47]. Voriconazole $1 \%$ has a good penetration and tolerability, although its activity was lower than natamycin against Fusarium keratitis in comparative studies [48]. Voriconazole has been used in regimens combining topical ( $10 \mathrm{mg} / \mathrm{mL}$ eye drops) and oral $(400 \mathrm{mg} / \mathrm{d})$ administration, with good results, particularly when a hypopyon is present. This regimen is considered useful to prevent dissemination and development of endophthalmitis [48]. AlHatmi et al recently observed a significant in vitro synergy of natamycin with voriconazole, itraconazole or micafungin [49]. Prajna et al reported equal or inferior efficacy of $1 \%$ voriconazole compared with $5 \%$ natamycin eye drops in a clinical trial, although in cases of Fusarium keratitis natamycin is known to be significantly more active than voriconazole [44,50,51].

In vitro and in vivo studies show that posaconazole has a broad spectrum against many fungi, including Fusarium spp., and is effective against most agents that are resistant to itraconazole and fluconazole [52,53]. Experience with its use in ocular infections is still limited, but initial results are encouraging. In one case report, F. solani did not respond to treatment with natamycin and amphotericin B, but responded to posaconazole with $200 \mathrm{mg} 4$ times daily associated with topical use $(100 \mathrm{mg} / \mathrm{mL}$ prepared from an oral solution), and the patient completely recovered [54]. Tu et al described three cases of keratitis due to F. solani that were progressing to endophthalmitis and unresponsive to treatment with oral and topical voriconazole, and a rapid therapeutic response to posaconazole was achieved [55].

Other drugs that have been tested for Fusarium include topical miconazole, which proved effective in an experimental study with less frequent dosing (1.2 to $10 \mathrm{mg}$ ) and can be used for topical administration as a $1 \%(10 \mathrm{mg} / \mathrm{mL})$ solution mainly for superficial infections [56]. Further comparative controlled studies are needed to demonstrate the real benefits of this drug.

\section{Deep infections}

Over the last two decades there has been a progressive increase in the incidence of invasive Fusarium infections in severely compromised patients. Patients with the highest risk are those with haematological malignancy, intensive chemotherapy and/or a corticosteroid regimen, recipients of solid organ or stem cell transplant leading to prolonged and profound neutropenia of $<500$ cells $/ \mathrm{mm}^{3}$ and/or severe T-cell immunodeficiency [57]. Environmental factors also play a role, e.g. contamination of water reservoirs has been the cause of hospital outbreaks with Fusarium $[58,59]$. Patients with disseminated fusariosis frequently present with lung involvement, positive blood cultures, metastatic skin lesions, and cellulitis [60]. Notably, positive serum galactomannan antigen testing has been reported in some patients with documented invasive fusariosis [61]. Despite advances in therapy and early diagnosis, invasive fusariosis remains associated with high morbidity and up to $70 \%$ mortality [7].

Prior to the voriconazole era, the initial approach to treating invasive fusariosis was to administer high-dose ( $>5 \mathrm{mg} / \mathrm{kg} / \mathrm{d})$ liposomal amphotericin B [7,62]. Some retrospective studies involving patients with invasive fusariosis and haematological malignancies treated with amphotericin B (either deoxycholate or lipid formulations) showed improvement in $32-46 \%$ of patients, and of those patients, only 13-21\% were still alive 90 days after diagnosis [63-65]. However, the overall response rates in immunocompromised hosts were dismal. In addition, few animal studies have been conducted to evaluate the effectiveness of amphotericin B, which did not prove to be effective either in neutropenic or immunocompetent animals [7,66-68]. After FDA approval in 2002, voriconazole became the firstline treatment [69]. Voriconazole is preferred to amphotericin B because of its lower toxicity and higher clinical efficacy against fusariosis [70]. Muhammed et al reported that voriconazole is effective in treating fusariosis, particularly when intolerance to, or failure of, the amphotericin B formulation warrants the use of voriconazole [24]. Nucci et al suggested using liposomal AMB ( $3 \mathrm{mg} / \mathrm{kg} / \mathrm{d}$ ) as first-line therapy, while intravenous voriconazole is used at a loading dose of $6 \mathrm{mg} / \mathrm{kg}$ every $12 \mathrm{~h}$ for two doses [71]. For some patients, this combination is used as first-line therapy before antifungal susceptibility testing results are available because of the variable susceptibility of Fusarium spp. to antifungal agents.

Perfect et al reported that voriconazole resulted in a favourable response in 5 (45\%) of 11 patients with fusariosis who were refractory to standard therapy [65]. Nucci et al reviewed 233 published cases from 11 countries, of which $92 \%$ had a haematological disease [57]. Treatment of systemic fusariosis was evaluated in two periods: 1985-2000 (period 1, $\mathrm{n}=121$ ) and 2001-2011 (period 2, $\mathrm{n}=112$ ). During period $1,63 \%(76 / 121)$ of patients were treated with deoxycholate amphotericin B, 18\% (22/121) with lipid formulations of amphotericin B and $2 \%(2 / 110)$ with voriconazole. In contrast, voriconazole $(36 / 112,32 \%)$ was more frequently used in period 2 compared with deoxycholate amphotericin B (34/121, 30\%), and lipid formulations of amphotericin B (12/112, 11\%). The 90-day 
probability of survival in periods 1 and 2 was $22 \%$ and $43 \%$, respectively. Combination therapy of voriconazole plus a lipid formulation of amphotericin B was used in 21 patients. In period 2, the 90-day probability of survival was $60 \%$ in patients treated with voriconazole, $53 \%$ in those treated with a lipid formulation of amphotericin B, and $28 \%$ in those treated with deoxycholate amphotericin $\mathrm{B}$. Open-label and compassionate clinical trials have demonstrated that voriconazole shows excellent activity against the majority of Fusarium species [72]. Voriconazole treatment is associated with a survival rate of approximately $40 \%$ compared with the historical $10 \%$ success rate of amphotericin B [73]. In addition, voriconazole is available in both oral (tablet and suspension) and intravenous formulations, with a bioavailability of greater than $90 \%$ with the oral drugs.

Posaconazole has been recommended for prophylaxis against fungal infections in neutropenic patients [74]. It proved to be effective in animal models of invasive fusariosis caused by isolates with reduced in vitro susceptibility [75]. A study of 21 patients with haematological malignancies initially treated with amphotericin B, which was associated with severe infusion-related toxicity and nephrotoxicity, showed a $50 \%$ overall response to posaconazole [15]. Several studies showed that patients responded favourably to posaconazole, which has been proposed for salvage therapy of disseminated fusariosis in patients who were refractory to conventional therapy or with intolerance to amphotericin B [16,76-79]. Notably, breakthrough Fusarium solani infection in a patient with acute myeloid leukaemia on posaconazole prophylaxis has been reported [78].

Isavuconazole has MICs equivalent to, or higher than, other triazoles against Fusarium species [23]. In two clinical trials (SECURE and VITAL), 7 patients with fusariosis were treated with isavuconazole as primary therapy, resulting in 44\% 90-day survival [80]. Fusarium species are intrinsically resistant to echinocandins (caspofungin, micafungin, and anidulafungin) with MICs of $>16 \mathrm{mg} / \mathrm{L}$ [2]. Surprisingly, caspofungin was recently reported to cure a breakthrough Fusarium fungaemia in a patient with acute leukaemia treated with amphotericin B [81]. Recently, Hassler et al reported on treatment of 10 patients with prolonged neutropenia and invasive fusariosis [82]. The treatment consisted of voriconazole as monotherapy $(\mathrm{n}=2)$ and combination therapy of voriconazole, either with a lipid formulation of amphotericin $B(n=5)$ or an echinocandin $(\mathrm{n}=3)$, with an overall $50 \%$ survival.

Antifungal combinations for fusariosis have not been evaluated using animal models or in clinical trial settings. Data on combination therapy for fusariosis are limited to a few case reports with amphotericin B deoxycholate plus voriconazole, caspofungin plus amphotericin B deoxycholate, and amphotericin B deoxycholate plus terbinafine [83-87]. In vitro combination of amphotericin $\mathrm{B}$ and ravuconazole has synergistic interaction against clinical isolates of Fusarium [88]. Spader et al reported synergy for the combinations of amphotericin B with caspofungin (68.7\%), amphotericin B with rifampin (68.7\%), amphotericin B with 5-flucytosine (59.3\%), and amphotericin B with voriconazole (37.5\%) [89]. However, in one study, the majority of Fusarium isolates tested using the combination of amphotericin B and voriconazole displayed neither a synergistic nor an antagonistic interaction between these two antifungal agents [90]. Recently, Martin-Vicente et al reported on double and triple in vitro combinations for strains belonging to the $\mathrm{Fu}$ sarium solani complex [91]. All of the double combinations showed a high percentage of synergy against this species, with anidulafungin/ voriconazole and amphotericin/anidulafungin being the most active (87.5\% synergy). Amphotericin/voriconazole showed $62.5 \%$ synergy. The triple combination (voriconazole/amphotericin/anidulafungin) showed $87.5 \%$ synergy.

When possible, antifungal treatment should be combined with surgery and reversal of immunosuppression. In 2014, the European
Fungal Infection Study Group and the European Confederation of Medical Mycology recommended voriconazole or a lipid formulation of amphotericin B with strong (AII) and moderate (BII) support, respectively, as optimal management for invasive fusariosis [92]. Nucci et al demonstrated a $21 \%$ increase in survival rate of invasive fusariosis during the last decade, associated with the use of voriconazole, either alone or in combination with other therapies [57].

Novel identification tools, such as MALDI-TOF MS, or nonculture diagnostic assays, enable both accurate and fast identification of Fusarium species in the clinical laboratory: further insight into antifungal susceptibility profiles associated with each species should help to choose an adequate first-line antifungal treatment and thus improve the prognosis of invasive fusariosis patients [93]. Susceptibility testing of clinical isolates is highly recommended in the clinical setting, not only because there are significant strain- and species-specific differences in antifungal susceptibility, but also for epidemiological studies to detect emergence of resistant strains [94]. Further data from animal models and clinical trials evaluating the optimal treatment strategy against Fusarium infections are needed to refine and improve treatment guidelines, which are currently based on data from relatively large, but uncontrolled case series.

Funding: No funding.

Competing interests: JFM and PEV have served as consultants to, and have received research grants and speaker fees from, Astellas, Basilea, Gilead Sciences, Merck, and Pfizer. All other authors declare that they have no conflict of interests.

Ethical approval: Not required.

\section{References}

[1] Mikami R, Stemmermann GN. Keratomycosis caused by Fusarium oxysporum. Am J Clin Pathol 1958;29:257-62.

[2] Al-Hatmi AM, Meis JF, de Hoog GS. Fusarium: molecular diversity and intrinsic drug resistance. PLoS Pathog 2016;12:e1005464.

[3] O’Donnell K, Rooney AP, Proctor RH, Brown DW, McCormick SP, Ward TJ, et al. Phylogenetic analyses of RPB1 and RPB2 support a middle Cretaceous origin for a clade comprising all agriculturally and medically important fusaria. Fungal Genet Biol 2013;52:20-31

[4] de Hoog GS, Chaturvedi V, Denning DW, Dyer PS, Frisvad JC, Geiser D, et al. Name changes in medically important fungi and their implications for clinical practice. J Clin Microbiol 2015;53:1056-62.

[5] Geiser DM, Klich MA, Frisvad JC, Peterson SW, Varga J, Samson RA. The current status of species recognition and identification in Aspergillus. Stud Mycol 2007;59:1-10.

[6] Nucci M, Anaissie E. Fusarium infections in immunocompromised patients. Clin Microbiol Rev 2007;20:695-704.

[7] Ortoneda M, Capilla J, Pastor FJ, Pujol I, Guarro J. Efficacy of liposomal amphotericin B in treatment of systemic murine fusariosis. Antimicrob Agents Chemother 2002;46:2273-5.

[8] van Diepeningen AD, Feng P, Ahmed S, Sudhadham M, Bunyaratavej S, de Hoog GS. Spectrum of Fusarium infections in tropical dermatology evidenced by multilocus sequencing typing diagnostics. Mycoses 2015;58:48-57.

[9] Bhatt VR, Viola GM, Ferrajoli A. Invasive fungal infections in acute leukemia. Ther Adv Hematol 2011;2:231-47.

[10] Al-Hatmi AM, Hagen F, Menken SBJ, Meis JF, de Hoog GS. Global molecular epidemiology and genetic diversity of Fusarium, a significant emerging human opportunist from 1958 to 2015. Emerg Microbes Infect 2016;5:e33.

[11] Espinel-Ingroff A, Colombo AL, Cordoba S, Dufresne PJ, Fuller J, Ghannoum M, et al. International evaluation of MIC distributions and epidemiological cutoff value (ECV) definitions for Fusarium species identified by molecular methods for the CLSI broth microdilution method. Antimicrob Agents Chemother 2016;60:1079-84.

[12] O’Donnell K, Sutton DA, Fothergill A, McCarthy D, Rinaldi MG, Brandt ME, et al. Molecular phylogenetic diversity, multilocus haplotype nomenclature, and in vitro antifungal resistance within the Fusarium solani species complex. J Clin Microbiol 2008;46:2477-90.

[13] Dalyan Cilo B, Al-Hatmi AM, Seyedmousavi S, Rijs AJ, Verweij PE, Ener B, et al. Emergence of fusarioses in a university hospital in Turkey during a 20-year period. Eur J Clin Microbiol Infect Dis 2015;34:1683-91.

[14] Pfaller MA, Messer SA, Woosley LN, Jones RN, Castanheira M. Echinocandin and triazole antifungal susceptibility profiles of opportunistic yeast and mold clinical isolates collected from 2010 to 2011: application of new CLSI clinical breakpoints and epidemiological cutoff values for characterization of geographic and temporal trends of antifungal resistance. J Clin Microbiol 2013;51:257181. 
[15] Raad II, Hachem RY, Herbrecht R, Graybill JR, Hare R, Corcoran G, et al. Posaconazole as salvage treatment for invasive fusariosis in patients with underlying hematologic malignancy and other conditions. Clin Infect Dis 2006;42:1398-403.

[16] Campo M, Lewis RE, Kontoyiannis DP. Invasive fusariosis in patients with hematologic malignancies at a cancer center: 1998-2009. J Infect 2010;60:3317

[17] Meis JF, Chowdhary A, Rhodes JL, Fisher MC, Verweij PE. Clinical implications of globally emerging azole resistance in Aspergillus fumigatus. Philos Trans R Soc Lond B Biol Sci 2016;371:20150460.

[18] Rodrigues AM, de Hoog GS, de Cássia Pires D, Brihante RS, Sidrim JJ, Gadelha MF, et al. Genetic diversity and antifungal susceptibility profiles in causative agents of sporotrichosis. BMC Infect Dis 2014;14:219.

[19] Selmecki A, Forche A, Berman J. Aneuploidy and isochromosome formation in drug-resistant Candida albicans. Science 2006;313:367-70.

[20] Sionov E, Lee H, Chang YC, Kwon-Chung KJ. Cryptococcus neoformans overcomes stress of azole drugs by formation of disomy in specific multiple chromosomes. PLoS Pathog 2010;6:e1000848.

[21] Verweij PE, Zhang J, Debets AJM, Meis JF, van de Veerdonk FL, Schoustra SE, et al. In-host adaptation and acquired triazole resistance in Aspergillus fumigatus: a dilemma for clinical management. Lancet Infect Dis 2016;16: e251-60.

[22] Pujol I, Guarro J, Gené J, Sala J. In-vitro antifungal susceptibility of clinical and environmental Fusarium spp. strains. J Antimicrob Chemother 1997;39:163-7.

[23] Al-Hatmi AM, van Diepeningen AD, Curfs-Breuker I, de Hoog GS, Meis JF. Specific antifungal susceptibility profiles of opportunists in the Fusarium fujikuroi complex. J Antimicrob Chemother 2015;70:1068-71.

[24] Muhammed M, Coleman JJ, Carneiro HA, Mylonakis E. The challenge of managing fusariosis. Virulence 2011;2:91-6

[25] Ranawaka RR, Nagahawatte A, Gunasekara TA. Fusarium onychomycosis: prevalence, clinical presentations, response to itraconazole and terbinafine pulse therapy, and 1-year follow-up in nine cases. Int J Dermatol 2015;54:1275-82.

[26] Bonifaz A, Cruz-Aguilar P, Ponce RM. Onychomycosis by molds. Report of 78 cases. Eur J Dermatol 2007;17:70-2.

[27] Verrier J, Bontems O, Baudraz-Rosselet F, Monod M. Oral terbinafine and itraconazole treatments against dermatophytes appear not to favor the establishment of Fusarium spp. in nail. Dermatology 2014;228:225-32.

[28] Varon AG, Nouer SA, Barreiros G, Trope BM, Magalhães F, Akiti T, et al. Superficial skin lesions positive for Fusarium are associated with subsequent development of invasive fusariosis. J Infect 2014;68:85-9.

[29] Galletti J, Negri M, Grassi FL, Kioshima-Cotica ÉS, Svidzinski TI. Fusarium spp. is able to grow and invade healthy human nails as a single source of nutrients. Eur J Clin Microbiol Infect Dis 2015;34:1767-72.

[30] Al-Hatmi AM, Bonifaz A, Calderón L, Curfs-Breuker I, Meis JF, van Diepeningen $\mathrm{AD}$, et al. Proximal subungual onychomycosis caused by Fusarium falciforme successfully cured with posaconazole. Br J Dermatol 2015;173:253-5.

[31] Badali H, Mohammadi R, Mashedi O, de Hoog GS, Meis JF. In vitro susceptibility patterns of clinically important Trichophyton and Epidermophyton species against nine antifungal drugs. Mycoses 2015;58:303-7.

[32] Bueno JG, Martinez C, Zapata B, Sanclemente G, Gallego M, Mesa AC, et al. In vitro activity of fluconazole, itraconazole, voriconazole and terbinafine against fungi causing onychomycosis. Clin Exp Dermatol 2010;35:658-63.

[33] Silva LB, de Oliveira DB, da Silva BV, de Souza RA, da Silva PR, Ferreira-Paim K, et al. Identification and antifungal susceptibility of fungi isolated from dermatomycoses. J Eur Acad Dermatol Venereol 2014;28:633-40.

[34] Taj-Aldeen SJ, Salah H, Al-Hatmi AM, Hamed M, Theelen B, van Diepeningen $A D$, et al. In vitro resistance of clinical Fusarium species to amphotericin $B$ and voriconazole using the EUCAST antifungal susceptibility method. Diagn Microbiol Infect Dis 2016;85:438-43.

[35] Lurati M, Baudraz-Rosselet F, Vernez M, Spring P, Bontems O, Fratti M, et al. Efficacious treatment of non-dermatophyte mould onychomycosis with topical amphotericin B. Dermatology 2011;223:289-92.

[36] Ghosh AK, Gupta A, Rudramurthy SM, Paul S, Hallur VK, Chakrabarti A. Fungal keratitis in North India: spectrum of agents, risk factors and treatment. Mycopathologia 2016;181:843-50.

[37] Al-Hatmi AM, Bonifaz A, de Hoog GS, Vazquez-Maya L, Garcia-Carmona K, Meis JF, et al. Keratitis by Fusarium temperatum, a novel opportunist. BMC Infect Dis 2014;14:588.

[38] do Carmo A, Costa E, Marques M, Quadrado MJ, Tomé R. Fusarium dimerum species complex (Fusarium penzigii) keratitis after corneal trauma. Mycopathologia 2016;181:879-84.

[39] Tupaki-Sreepurna A, Al-Hatmi AM, Kindo AJ, Sundaram M, de Hoog GS. Multidrug-resistant Fusarium in keratitis: a clinico-mycological study of keratitis infections in Chennai, India. Mycoses 2017:60:230-3.

[40] Hu J, Zhang J, Li Y, Han X, Zheng W, Yang J, et al. A combination of intrastromal and intracameral injections of amphotericin B in the treatment of severe fungal keratitis. J Ophthalmol 2016;2016:3436415.

[41] Sharma N, Sankaran P, Agarwal T, Arora T, Chawla B, Titiyal JS, et al. Evaluation of amphotericin B in the management of fungal keratitis: randomized controlled trial. Ocul Immunol Inflamm 2016;24:493-7.

[42] Fu T, Yi J, Lv S, Zhang B. Ocular amphotericin B delivery by chitosan-modified nanostructured lipid carriers for fungal keratitis-targeted therapy. J Liposome Res 2017;27:228-33.

[43] Lalitha P, Sun CQ Prajna NV, Karpagam R, Geetha M, O’Brien KS, et al. In vitro susceptibility of filamentous fungal isolates from a corneal ulcer clinical trial. Am J Ophthalmol 2014;157:318-26.
[44] Sharma S, Das S, Virdi A, Fernandes M, Sahu SK, Kumar Koday N, et al. Reappraisal of topical $1 \%$ voriconazole and $5 \%$ natamycin in the treatment of fungal keratitis in a randomised trial. Br J Ophthalmol 2015;99:1190-5.

[45] O’Day DM, Robinson RD, Head WS. Efficacy of anti-fungal agents in the cornea. I. A comparative study. Invest Ophthalmol Vis Sci 1983;24:1098-102.

[46] Lalitha P, Shapiro BL, Srinivasan M, Prajna NV, Acharya NR, Fothergill AW, et al. Antimicrobial susceptibility of Fusarium, Aspergillus, and other filamentous fungi isolated from keratitis. Arch Ophthalmol 2007;125:789-93.

[47] Prajna NV, Mascarenhas J, Krishnan T, Reddy PR, Prajna L, Srinivasan M, et al. Comparison of natamycin and voriconazole for the treatment of fungal keratitis. Arch Ophthalmol 2010;128:672-8.

[48] Prajna NV, Krishnan T, Rajaraman R, Patel S, Srinivasan M, Das M, et al. Effect of oral voriconazole on fungal keratitis in the mycotic ulcer treatment trial II (MUTT II): a randomized clinical trial. JAMA Ophthalmol 2016;134:1365-72.

[49] Al-Hatmi AM, Meletiadis J, Curfs-Breuker I, Bonifaz A, Meis JF, De Hoog GS. In vitro combinations of natamycin with voriconazole, itraconazole and micafungin against clinical Fusarium strains causing keratitis. J Antimicrob Chemother 2016;71:953-5

[50] Prajna NV, Krishnan T, Mascarenhas J, Rajaraman R, Prajna L, Srinivasan M, et al. The mycotic ulcer treatment trial: a randomized trial comparing natamycin vs voriconazole. JAMA Ophthalmol 2013;131:422-9.

[51] Sun CQ, Lalitha P, Prajna NV, Karpagam R, Geetha M, O’Brien KS, et al. Association between in vitro susceptibility to natamycin and voriconazole and clinical outcomes in fungal keratitis. Ophthalmology 2014;121:1495-500.

[52] Cuenca-Estrella M, Gomez-Lopez A, Mellado E, Buitrago MJ, Monzon A, Rodriguez-Tudela JL. Head-to-head comparison of the activities of currently available antifungal agents against 3,378 Spanish clinical isolates of yeasts and filamentous fungi. Antimicrob Agents Chemother 2006;50:917-21.

[53] Torres HA, Hachem RY, Chemaly RF, Kontoyiannis DP, Raad II. Posaconazole: a broad-spectrum triazole antifungal. Lancet Infect Dis 2005;5:775-85.

[54] Sponsel WE, Graybill JR, Nevarez HL, Dang D. Ocular and systemic posaconazole (SCH-56592) treatment of invasive Fusarium solani keratitis and endophthalmitis. Br J Ophthalmol 2002;86:829-30.

[55] Tu EY, McCartney DL, Beatty RF, Springer KL, Levy J, Edward D. Successful treatment of resistant ocular fusariosis with posaconazole (SCH-56592). Am J Ophthalmol 2007;143:222-7.

[56] Thomas PA. Current perspectives on ophthalmic mycoses. Clin Microbiol Rev 2003;16:730-97.

[57] Nucci M, Marr KA, Vehreschild MJ, de Souza CA, Velasco E, Cappellano P, et al. Improvement in the outcome of invasive fusariosis in the last decade. Clin Microbiol Infect 2014;20:580-5.

[58] Garnica M, daCunha OM, Portugal R, Maiolino A, Colombo AL, Nucci M. Risk factors for invasive fusariosis in patients with acute myeloid leukemia and in hematopoietic cell transplant recipients. Clin Infect Dis 2015;60:875-80.

[59] Litvinov N, da Silva MT, van der Heijden IM, Graça MG, Marques de Oliveira L, Fu L, et al. An outbreak of invasive fusariosis in a children's cancer hospital. Clin Microbiol Infect 2015;21:268, e1-7.

[60] Varon AG, Nouér SA, Barreiros G, Trope BM, Akiti T, Nucci M. Antimold prophylaxis may reduce the risk of invasive fusariosis in hematologic patients with superficial skin lesions with positive culture for Fusarium. Antimicrob Agents Chemother 2016;60:7290-4

[61] Nucci M, Carlesse F, Cappellano P, Varon AG, Seber A, Garnica M, et al. Earlier diagnosis of invasive fusariosis with Aspergillus serum galactomannan testing. PLoS ONE 2014;9:e87784.

[62] Lortholary O, Fernández-Ruiz M, Perfect JR. The current treatment landscape: other fungal diseases (cryptococcosis, fusariosis and mucormycosis). J Antimicrob Chemother 2016:71(Suppl. 2):ii31-6.

[63] Nucci M, Anaissie E, Queiroz-Telles F, Martins CA, Trabasso P, Solza C, et al. Outcome predictor of 84 patients with hematologic malignancies and Fusarium infection. Cancer 2003;98:315-19.

[64] Nucci M, Marr KA, Queiroz-Telles F, Martins CA, Trabasso P, Costa S, et al. Fusarium infection in hematopoietic stem cell transplant recipients. Clin Infect Dis 2004;38:1237-42.

[65] Perfect JR, Marr KA, Walsh TJ, Greenberg RN, DuPont B, de la Torre-Cisneros J, et al. Voriconazole treatment for less-common, emerging, or refractory fungal infections. Clin Infect Dis 2003;36:1122-31.

[66] Ruíz-Cendoya M, Mariné M, Guarro J. Combined therapy in treatment of murine infection by Fusarium solani. J Antimicrob Chemother 2008;62:543-6.

[67] Ruíz-Cendoya M, Mariné M, Rodriguez MM, Guarro J. Interactions between triazoles and amphotericin B in treatment of disseminated murine infection by Fusarium oxysporum. Antimicrob Agents Chemother 2009;53:1705-8.

[68] Guarro J, Pujol I, Mayayo E. In vitro and in vivo experimental activities of antifungal agents against Fusarium solani. Antimicrob Agents Chemother 1999;43:1256-7.

[69] Stempel JM, Hammond SP, Sutton DA, Weiser LM, Marty FM. Invasive fusariosis in the voriconazole era: single-center 13-year experience. Open Forum Infect Dis 2015;2:ofv099.

[70] Walsh TJ1, Hiemenz JW, Seibel NL, Perfect JR, Horwith G, Lee L, et al. Amphotericin B lipid complex for invasive fungal infections: analysis of safety and efficacy in 556 cases. Clin Infect Dis 1998;26:1383-96.

[71] Nucci M, Anaissie E. How we treat invasive fungal diseases in patients with acute leukemia: the importance of an individualized approach. Blood 2014;124:3858-69.

[72] Lortholary O, Obenga G, Biswas P, Caillot D, Chachaty E, Bienvenu A, et al. International retrospective analysis of 73 cases of invasive fusariosis treated with voriconazole. Antimicrob Agents Chemother 2010;54:4446-50. 
[73] Vazquez JA, Miceli MH, Alangaden G. Invasive fungal infections in transplant recipients. Ther Adv Infect Dis 2013;1:85-105.

[74] Cornely OA, Maertens J, Winston DJ, Perfect J, Ullmann AJ, Walsh TJ, et al. Posaconazole vs. fluconazole or itraconazole prophylaxis in patients with neutropenia. N Engl J Med 2007;356:348-59.

[75] Wiederhold NP, Najvar LK, Bocanegra R, Graybill JR, Patterson TF. Efficacy of posaconazole as treatment and prophylaxis against Fusarium solani. Antimicrob Agents Chemother 2010;54:1055-9.

[76] Miceli MH, Lee SA. Emerging moulds: epidemiological trends and antifungal resistance. Mycoses 2011;54:e666-78.

[77] Horn DL, Freifeld AG, Schuster MG, Azie NE, Franks B, Kauffman CA. Treatment and outcomes of invasive fusariosis: review of 65 cases from the PATH Alliance( $\left({ }^{\circledR}\right)$ registry. Mycoses 2014;57:652-8.

[78] Wu CH, Lu PL, Hsiao HH, Liu TC, Lin SF, Chang CS, et al. Breakthrough Fusarium solani infection in a patient with acute myeloid leukemia receiving posaconazole prophylaxis. Ann Hematol 2014;93:1079-81.

[79] Herbrecht R, Kessler R, Kravanja C, Meyer MH, Waller J, Letscher-Bru V. Successful treatment of Fusarium proliferatum pneumonia with posaconazole in a lung transplant recipient. J Heart Lung Transplant 2004;23:1451-4.

[80] Cornely OA, Ostrosky-Zeichner L, Rahav G, Mahar R, Zeiher B, Lee M, et al. Outcomes in patients with invasive mold disease caused by Fusarium or Scedosporium spp. treated with isavuconazole: experience from the VITAL and SECURE trials. Presented at: 54th Interscience Conference on Antimicrobial Agents and Chemotherapy (ICAAC) ASM. Washington, DC, USA, 5-9 September 2014 (Abstract no. M-1760).

[81] Apostolidis J, Bouzani M, Platsouka E, Belasiotou H, Stamouli M, Harhalakis N, et al. Resolution of fungemia due to Fusarium species in a patient with acute leukemia treated with caspofungin. Clin Infect Dis 2003;36:1349-50.

[82] Hassler A, Lieb A, Seidel D, Cesaro S, Greil J, Klimko N, et al. Disseminated fusariosis in immunocompromised children-analysis of recent cases identified in the global FungiScope registry. Pediatr Infect Dis J 2017;36:230-1.

[83] Guzman-Cottrill JA, Zheng X, Chadwick EG. Fusarium solani endocarditis successfully treated with liposomal amphotericin B and voriconazole. Pediatr Infect Dis J 2004;23:1059-61.
[84] Durand-Joly I, Alfandari S, Benchikh Z, Rodrigue M, Espinel-Ingroff A, Catteau $B$, et al. Successful outcome of disseminated Fusarium infection with skin localization treated with voriconazole and amphotericin B-lipid complex in a patient with acute leukemia. J Clin Microbiol 2003;41:4898900.

[85] Ho DY, Lee JD, Rosso F, Montoya JG. Treating disseminated fusariosis: amphotericin B, voriconazole or both? Mycoses 2007;50:227-31.

[86] Makowsky MJ, Warkentin DI, Savoie ML. Caspofungin and amphotericin B for disseminated Fusarium verticillioides in leukemia. Ann Pharmacother 2005;39:1365-6.

[87] Rothe A, Seibold M, Hoppe T, Seifert H, Engert A, Caspar C, et al. Combination therapy of disseminated Fusarium oxysporum infection with terbinafine and amphotericin B. Ann Hematol 2004;83:394-7.

[88] Ortoneda M, Capilla J, Pastor FJ, Pujol I, Guarro J. In vitro interactions of licensed and novel antifungal drugs against Fusarium spp. Diagn Microbiol Infect Dis 2004;48:69-71.

[89] Spader TB, Venturini TP, Rossato L, Denardi LB, Cavalheiro PB, Botton SA, et al. Synergysm of voriconazole or itraconazole with other antifungal agents against species of Fusarium. Rev Iberoam Micol 2013;30:200-4.

[90] Córdoba S, Rodero L, Vivot W, Abrantes R, Davel G, Vitale RG. In vitro interactions of antifungal agents against clinical isolates of Fusarium spp. Int J Antimicrob Agents 2008;31:171-4.

[91] Martin-Vicente A, Guarro J, Capilla J. Does a triple combination have better activity than double combinations against multiresistant fungi? Experimental in vitro evaluation. Int J Antimicrob Agents 2017;49:422-6.

[92] Tortorano AM, Richardson M, Roilides E, van Diepeningen A, Caira M, Munoz $P$, et al. ESCMID and ECMM joint guidelines on diagnosis and management of hyalohyphomycosis: Fusarium spp., Scedosporium spp. and others. Clin Microbiol Infect 2014;20(Suppl. 3):27-46.

[93] Al-Hatmi AM, Normand AC, van Diepeningen AD, Hendrickx M, de Hoog GS, Piarroux R. Rapid identification of clinical members of Fusarium fujikuroi complex using MALDI-TOF MS. Future Microbiol 2015;10:1939-52.

[94] Al-Hatmi AM, Curfs-Breuker I, de Hoog GS, Meis JF, Verweij PE. Antifungal susceptibility testing of Fusarium: a practical approach. J Fungi 2017;3:19. 